\title{
Qualitative Study on the Process of Language Learning in Multilingual Families: A Survey on Parental Awareness
}

\author{
${\text { Dexia } \text { Yin }^{l} \text {, Katsuro Kitamura }}^{2}$ \\ Tohoku University $^{1}$, Nihon University ${ }^{2}$
}

\begin{abstract}
This paper examines, through the qualitative method, a Chinese couple living in Japan and conducts a qualitative analysis of the process in which the three children in the family learn multiple languages, including Chinese as their mother tongue, Japanese as the first language, and the English, which they each began at age three. It analyzes how the children use, manage and master these languages. In this study, semi-structured interview questions and field observation records are employed. Data is collected through follow-up questions with parents and observation and recording of the children's family interactions, and is analyzed through the guidelines established by Patton (2002). The main findings include: (1) overseas Chinese parents' equal emphasis upon the learning of English and their mother tongue; (2) the use and planning of languages in the parent-dominated environment; and (3) changes in the parents' communication awareness and participation patterns in the changing process of learning Chinese as a mother tongue as compared to a foreign language.
\end{abstract}

Keywords: Awareness in the use of multiple languages; multilingual competence; language planning; qualitative analysis 